Research Article

\title{
Failure Mechanism for Surrounding Rock of Deep Circular Roadway in Coal Mine Based on Mining-Induced Plastic Zone
}

\author{
Yue Yuan $\mathbb{D}^{1,2}$, Weijun Wang $\mathbb{D}^{3},{ }^{3}$ Shuqing $\mathrm{Li}\left(\mathbb{D},{ }^{1,2}\right.$ and Yongjian $\mathrm{Zhu}^{3}$ \\ ${ }^{1}$ Work Safety Key Lab on Prevention and Control of Gas and Roof Disasters for Southern Coal Mines, \\ Hunan University of Science and Technology, Xiangtan, Hunan, China \\ ${ }^{2}$ Hunan Provincial Key Laboratory of Safe Mining Techniques of Coal Mines, Hunan University of Science and Technology, \\ Xiangtan, Hunan, China \\ ${ }^{3}$ School of Resource, Environment and Safety Engineering, Hunan University of Science and Technology, Xiangtan, Hunan, China
}

Correspondence should be addressed to Yue Yuan; yuanyuekafu@163.com

Received 19 April 2018; Accepted 15 August 2018; Published 17 October 2018

Academic Editor: Stefano Sorace

Copyright (c) 2018 Yue Yuan et al. This is an open access article distributed under the Creative Commons Attribution License, which permits unrestricted use, distribution, and reproduction in any medium, provided the original work is properly cited.

In order to reveal the failure mechanism of the deep roadway under mining-induced pressure in coal mine, the boundary equations for the plastic zone around the deep roadway were deduced, and then the evolution laws for morphology of the plastic zone and the relationship between the morphological indexes and the stability of surrounding rock were discussed. The results show that, for the deep roadway, the effect of mining on the plastic zone is more sensitive than that on the shallow one. Even if the changes of mining influence are small, they may also cause extremely serious plastic failure of surrounding rock masses, leading to the sudden instability of the roadway. When the plastic wings of the plastic zone are approximately perpendicular to the roof, floor, or sidewall, the large deformation and failure of the deep roadway are very likely to occur. Compared with the index of the uniformity coefficient, the irregular shape coefficient can be used to better characterize the differences in the plastic zone morphology. Finally, a case study was provided to apply the principles for the formation and extension of a butterfly-shaped plastic zone.

\section{Introduction}

With the increasing shortage of coal resources in shallow depth, the mining depth of coal mine in China is increasing at a speed of $10-25 \mathrm{~m}$ per year. Currently, China has $47 \mathrm{coal}$ mines more than $1000 \mathrm{~m}$ deep [1-3]. Deep coal mining at $1000 \mathrm{~m}$ in other countries like Poland, Germany, Britain, and Japan is also common [4]. Compared with shallow mining, deep coal mining is confronted with some complicated problems such as large deformation, rockbursts, and water hazards [5-8]. Among them, the large deformation and failure of deep roadways threaten seriously mining production and safety [9].

In order to minimize the disasters, the first thing to be solved is the clarity of the failure mechanism for deep roadways or deep rock. In recent years, scholars have carried out a lot of research on it by using numerical simulation, model testing, theoretic analysis, etc. For example, Dolezalova et al. [10-16] used FEM, FLAC ${ }^{3 \mathrm{D}}$,
FDEM, and 3EDC to simulate stress distribution and failure evolution of deep engineering, respectively. In view of the nonlinear problems of large deformation occurring in a deep soft rock roadway, He [17] adopted the material point method (MPM) to simulate the large deformation and failure process of deep rocks. Geomechanical model test is also an important way to investigate the failure behavior of deep surrounding rock. Sun et al. [18-20] conducted large-scale model tests. For theoretical analysis, Wang et al. [21] developed a dynamic failure constitutive model to computer deep large deformation, and Zareifard and Fahimifar [22] deduced an analytical solution for the stresses and deformations of deep tunnels considering the damaged zone. By field detection, the failure characteristics of the deep rock were also obtained [23, 24]. Zhao et al. [25-28] performed rock creep tests under multilevel load and revealed the nonlinear relationships between the instantaneous strain, viscoelastic strain, viscoplastic strain, and high deviatoric stress. 
Large deformation and failure of deep roadways are not only related to high stress and weak rock masses but also closely associated with the mining-induced pressure (the side and front abutment pressure); thus, the influence of mining is sometimes a nonignorable factor [29, 30], whereas limited research studies $[31,32]$ have been carried out on the damage and failure of deep roadways subjected to mininginduced pressure.

Although the deformation and instability of deep roadways have been studied, the failure mechanism is still far from being complete and satisfactory. The previous research $[33,34]$ shows a close relation between the range and shape of the plastic zone and the stability of the roadway. Moreover, the plastic zone will be extended under the external extra load, which would result in the increase of unrestrained deformations and deterioration of the surrounding rock strength [35-40]. Therefore, the distribution and evolution of the plastic zone around the deep roadway under the secondary stress field is key to investigate its failure mechanism. In this work, the morphological evolution of the plastic zone and the relationship between the morphological indexes proposed and the stability of surrounding rock were explored.

\section{Failure Characteristics of Deep Roadway under Mining-Induced Pressure in Coal Mine}

For deep roadway, the high geostress and the intense mining activities nearby mainly lead to a quite nonuniform, complex stress field, which causes severe failure of the mininginfluenced deep roadway. The main failure characteristics of this kind of roadway are as follows:

(1) The roadway roof subsides sharply, which can reach 500 1200 mm, as shown in Figure 1(a). Part of rock masses in the top anchorage region slides down.

(2) The deformation of sidewalls is serious. Extruding magnitude of a single sidewall ranges from $400 \mathrm{~mm}$ to $800 \mathrm{~mm}$. Besides, the phenomenon of sidewall caving appears in some regions (Figure 1(b)).

(3) The obvious floor heave causes cracking of shotcrete lining and serious inclination of the brace and track; thus, the roadway cannot be used properly (Figure 1(c)).

(4) Influenced by high geostress, repeated mining activities, and geological structures, the deformation of the roadway surrounding rock appears significantly asymmetry, which hinders the utilization of the roadway (Figure $1(\mathrm{~d})$ ).

\section{Evolutionary Laws of Morphology for Plastic Zone around Deep Roadways under Mining-Induced Pressure}

\subsection{Evolution Equation for Boundary of Mining-Induced Plastic Zone}

3.1.1. Basic Assumptions and Mechanical Model. The deep gate roadways are often subjected to mining influence from their own working face and adjacent excavation, which contributes to the superposition of the initial stress field, abutment pressure, and other dynamic loads. Therefore, the regional stress field of deep gate roadways is quite complex. In order to solve problems conveniently, the following assumptions are made:

(1) The length of the roadway along the horizontal direction is infinite, with a circular cross section, the radius $R_{0}$, and the buried depth $H \geq 20 R_{0}$.

(2) The surrounding rock is considered the isotropic, homogeneous medium and an incompressible material in plasticity.

(3) The initial maximum and minimum principal stresses of the roadway are $P_{1}$ and $P_{3}$, respectively, which are parallel to the coordinate axes, without consideration of the supporting force.

(4) Two parameters $D_{\varsigma 1}$ and $D_{\varsigma 3}$ (i.e., mining coefficients for the maximum and minimum principal stresses) that characterize the effect of mining on the initial principal stress are introduced. The principal stress field of the roadway changes with mining activities except for the stress direction. The mechanical model of the roadway is shown in Figure 2, and the surrounding rock can be divided into the plastic zone (radius equal to $R_{\mathrm{p}}$ ) and elastic zone from inside to outside.

\subsubsection{Boundary Equation of Plastic Zone (the Principle} Stresses Parallel to Coordinate Axes). The pressure (in Figure 2) acting on the surrounding rock is decomposed into two cases I and II, as shown in Figure 3.

For Case I, according to the theory of elasticity $[17,21]$, the elastic stress field of the roadway surrounding rock subjected to uniform pressure is as follows:

$$
\left\{\begin{array}{c}
\sigma_{\mathrm{r}}=\frac{\left(D_{\zeta 1} P_{1}+D_{\zeta 3} P_{3}\right)}{2}\left(1-\frac{R_{0}^{2}}{r^{2}}\right), \\
\sigma_{\theta}=\frac{\left(D_{\zeta 1} P_{1}+D_{\zeta 3} P_{3}\right)}{2}\left(1+\frac{R_{0}^{2}}{r^{2}}\right),
\end{array}\right.
$$

where $\sigma_{\mathrm{r}}$ and $\sigma_{\theta}$ are the radial stress and tangential stress at any point in surrounding rock under polar coordinates, respectively, and $r$ represents the radial coordinate of this point.

For Case II, the stress field of the surrounding rock is as follows:

$$
\left\{\begin{array}{l}
\sigma_{\mathrm{r}}=\frac{\left(D_{\zeta 3} P_{3}-D_{\varsigma 1} P_{1}\right)}{2} \cos 2 \theta\left(1-\frac{R_{0}^{2}}{r^{2}}\right)\left(1-3 \frac{R_{0}^{2}}{r^{2}}\right), \\
\sigma_{\theta}=-\frac{\left(D_{\zeta 3} P_{3}-D_{\zeta 1} P_{1}\right)}{2} \cos 2 \theta\left(1+3 \frac{R_{0}^{4}}{r^{4}}\right), \\
\tau_{\mathrm{r} \theta}=-\frac{\left(D_{\zeta 3} P_{3}-D_{\zeta 1} P_{1}\right)}{2} \sin 2 \theta\left(1-\frac{R_{0}^{2}}{r^{2}}\right)\left(1+3 \frac{R_{0}^{2}}{r^{2}}\right),
\end{array}\right.
$$




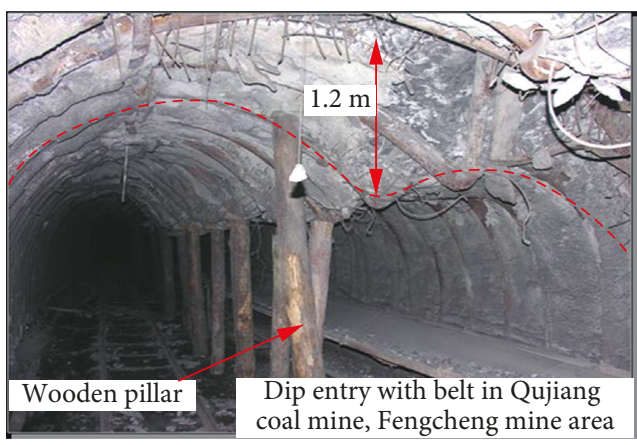

(a)

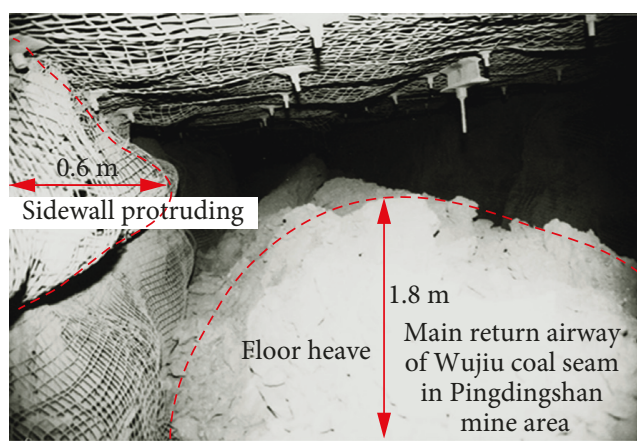

(c)

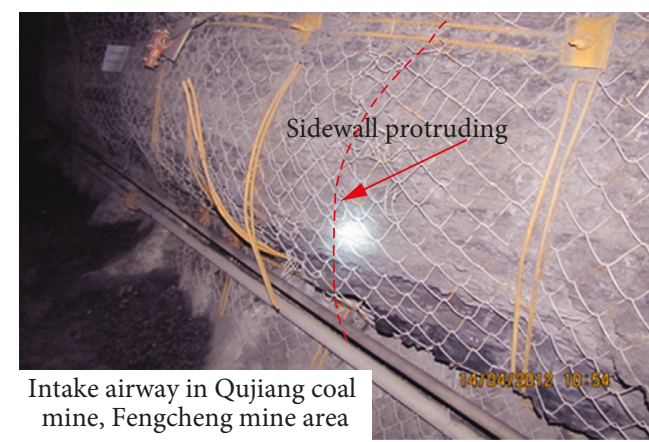

(b)

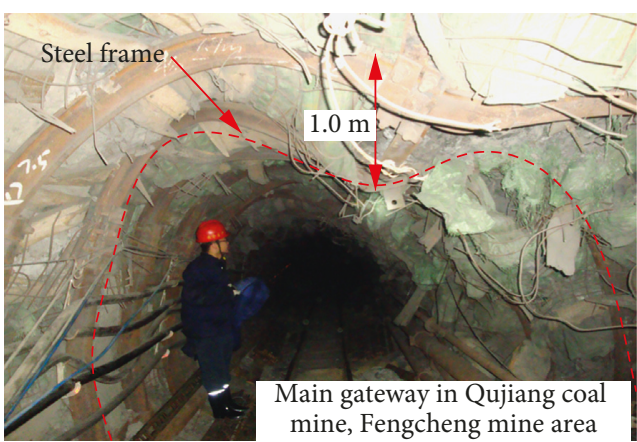

(d)

Figure 1: Main characteristics of deformation and failure for the deep roadway under mining-induced pressure.

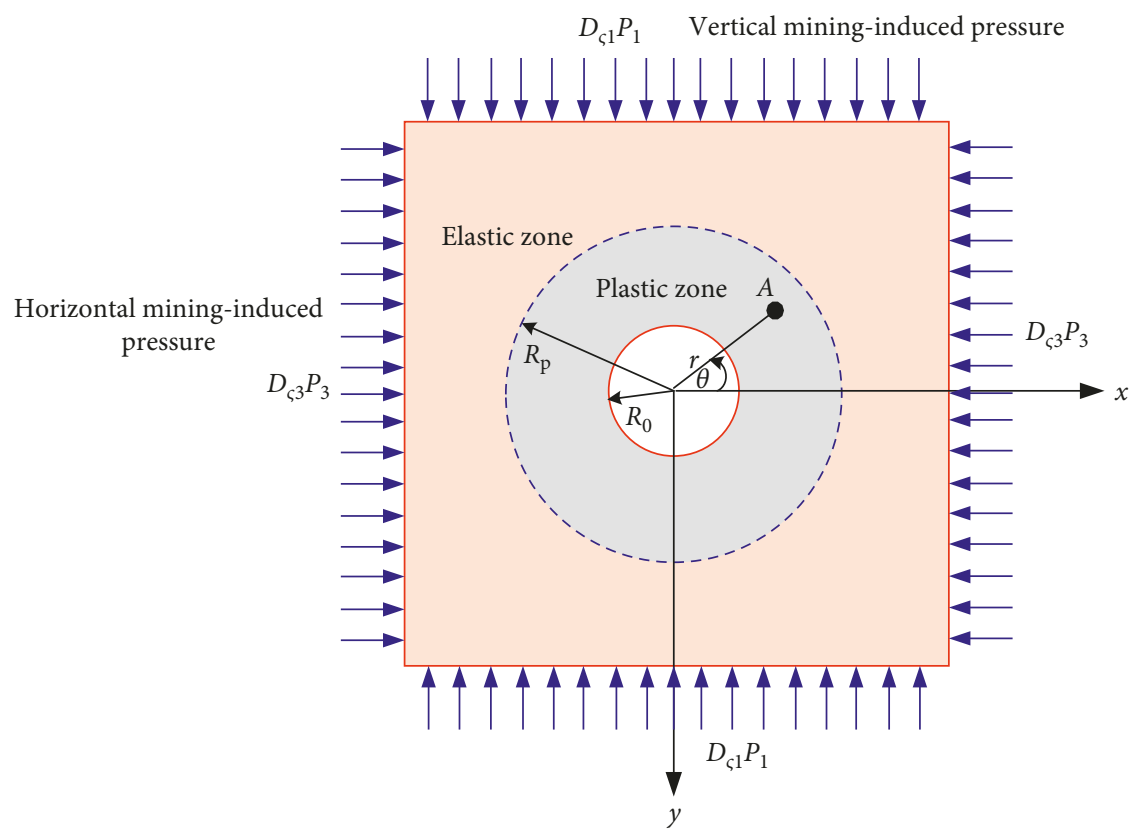

FIgURE 2: Mechanical model of the roadway. 

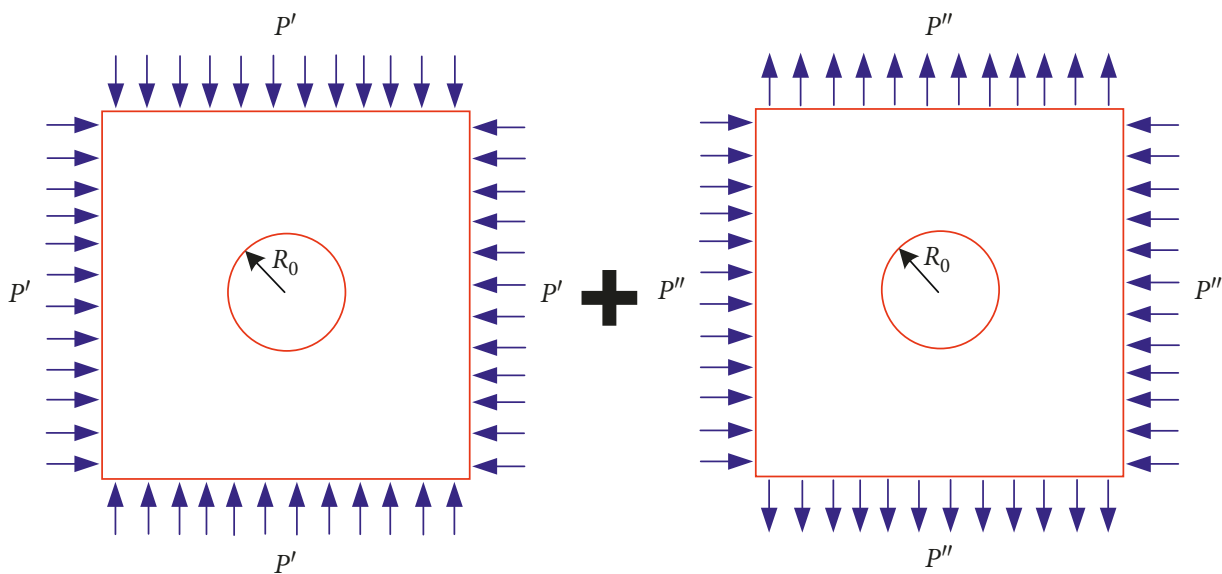

FIgURE 3: Decomposition of surrounding rock pressure for the roadway: (a) Case I and (b) Case II. $P^{\prime}=\left(D_{\varsigma 1} P_{1}+D_{\varsigma 3} P_{3}\right) / 2$; $P^{\prime \prime}=\left(D_{\varsigma 3} P_{3}-D_{\varsigma 1} P_{1}\right) / 2$.

where $\tau_{\mathrm{r} \theta}$ is the shear stress in polar coordinates and $\theta$ is the tangential coordinate of the point.

After superposition of the stress fields of surrounding rock in two different cases, the elastic stress field of the circular roadway subjected to mining-induced pressure can be obtained as follows:

$$
\left\{\begin{array}{l}
\sigma_{\mathrm{r}}=\left(1-\frac{R_{0}^{2}}{r^{2}}\right)\left[\frac{\left(D_{\zeta 1} P_{1}+D_{\zeta 3} P_{3}\right)}{2}+\frac{\left(D_{\zeta 3} P_{3}-D_{\zeta 1} P_{1}\right)}{2}\left(1-3 \frac{R_{0}^{2}}{r^{2}}\right) \cos 2 \theta\right], \\
\sigma_{\theta}=\frac{\left(D_{\zeta 1} P_{1}+D_{\zeta 3} P_{3}\right)}{2}\left(1+\frac{R_{0}^{2}}{r^{2}}\right)-\frac{\left(D_{\zeta 3} P_{3}-D_{\zeta 1} P_{1}\right)}{2}\left(1+3 \frac{R_{0}^{4}}{r^{4}}\right) \cos 2 \theta, \\
\tau_{\mathrm{r} \theta}=-\frac{\left(D_{\zeta 3} P_{3}-D_{\zeta 1} P_{1}\right)}{2} \sin 2 \theta\left(1-\frac{R_{0}^{2}}{r^{2}}\right)\left(1+3 \frac{R_{0}^{2}}{r^{2}}\right) .
\end{array}\right.
$$

In terms of the literatures [21,22], the polar expression of the Mohr-Coulomb yield criterion is

$$
\begin{aligned}
\frac{\left(\sigma_{\mathrm{r}}-\sigma_{\theta}\right)^{2}}{4}+\tau_{\mathrm{r} \theta}^{2}= & {\left[\frac{\left(\sigma_{\mathrm{r}}+\sigma_{\theta}\right)^{2}}{4}-c^{2}\right] \frac{(1-\cos 2 \varphi)}{2} } \\
& +c^{2}+\frac{\left(\sigma_{\mathrm{r}}+\sigma_{\theta}\right)}{2} c \cdot \sin 2 \varphi,
\end{aligned}
$$

where $c$ denotes the cohesion of the surrounding rock and $\varphi$ indicates the internal friction angle.

Assuming that $m=D_{\varsigma 1} P_{1}+D_{\varsigma 3} P_{3}, n=D_{\varsigma 3} P_{3}-D_{\varsigma 1} P_{1}$, $w=R_{0}^{2} / r^{2}$, and $t=n \cos 2 \theta$, substituting (3) into (4), the implicit function referred to $r$ and $\theta$ is obtained as follows [41]:

$$
\begin{aligned}
f(r, \theta)= & {\left[m w-t\left(1+3 w^{2}-2 w\right)\right]^{2} } \\
& +\left[n \sin 2 \theta\left(1-3 w^{2}+2 w\right)\right]^{2} \\
& -\left[(m-2 w t)^{2}-4 c^{2}\right] \frac{(1-\cos 2 \varphi)}{2}-4 c^{2} \\
& -2(m-2 w t) c \sin 2 \varphi .
\end{aligned}
$$

When $f(r, \theta)=0$, it becomes the interface between the elastic and plastic zones of the deep roadway, i.e., the equation for boundary of the plastic zone. Especially for $P_{1}=$ $P_{3}$ and $D_{\varsigma 1}=D_{\varsigma 3}=1$, the radius of the plastic zone around the circular roadway under uniform stress field can be obtained from formula (5), which is 


$$
R_{\mathrm{p}}=R_{0} \sqrt[4]{\frac{P_{1}^{2} \csc ^{2} \varphi}{\left(P_{1}^{2}-c^{2}\right)+c\left(c \csc ^{2} \varphi+2 P_{1} \cot \varphi\right)}} .
$$

\subsubsection{Boundary Equation of Plastic Zone (the Principle} Stresses with a Certain Rotation Angle). The engineering practice shows that not only the magnitude of principal stress of the roadway but also the direction of that will be changed due to the nearby coal mining. It is assumed that the deflection angle of the maximum principal stress $D_{c 1} P_{1}$ is $\beta$ relative to Figure 2, and the counterclockwise direction is positive. A new coordinate system $x^{\prime}-y^{\prime}$ is established, as shown in Figure 4.

In the new and old coordinates, the polar coordinates of any point $\mathrm{A}$ in the surrounding rock are $\left(r^{\prime}, \theta^{\prime}\right)$ and $(r, \theta)$, respectively. It is seen from Figure 4 that the rotation angle of the new coordinate axes relative to the old ones is $\beta$.

In the new coordinate system, the boundary equation of the plastic zone around the deep roadway under mininginduced pressure is similar to formula (5), given as follows:

$$
\begin{aligned}
f\left(r^{\prime}, \theta^{\prime}\right)= & {\left[m w^{\prime}-t^{\prime}\left(1+3 w^{\prime 2}-2 w^{\prime}\right)\right]^{2} } \\
& +\left[n \sin 2 \theta^{\prime}\left(1-3 w^{\prime 2}+2 w^{\prime}\right)=\right]^{2} \\
& -\left[\left(m-2 w^{\prime} t^{\prime}\right)^{2}-4 c^{2}\right] \frac{(1-\cos 2 \varphi)}{2}-4 c^{2} \\
& -2\left(m-2 w^{\prime} t^{\prime}\right) c \sin 2 \varphi,
\end{aligned}
$$

where $m=D_{\varsigma 1} P_{1}+D_{\varsigma 3} P_{3}, n=D_{\varsigma 3} P_{3}-D_{\varsigma 1} P_{1}, w^{\prime}=R_{0}^{2} / r^{\prime 2}$, and $t^{\prime}=n \cos 2 \theta^{\prime}$.

Note that the relationship between the new and old polar coordinates of any point $\mathrm{A}$ is $r^{\prime}=r$ and $\theta^{\prime}=\theta-\beta$; therefore, the implicit equation for the boundary of the plastic zone under deflection of the principal stress field can be obtained from formula (7), given as follows:

$$
\begin{aligned}
f(r, \theta)= & {\left[m w-t_{1}\left(1+3 w^{2}-2 w\right)\right]^{2} } \\
& +\left[n[\sin 2(\theta-\beta)]\left(1-3 w^{2}+2 w\right)\right]^{2} \\
& -\left[\left(m-2 w t_{1}\right)^{2}-4 c^{2}\right] \frac{(1-\cos 2 \varphi)}{2}-4 c^{2} \\
& -2\left(m-2 w t_{1}\right) c \sin 2 \varphi
\end{aligned}
$$

where $w=R_{0}^{2} / r^{2}$ and $t_{1}=n \cos 2(\theta-\beta)$.

3.2. Morphological Evolution of Plastic Zone around Roadway under Mining-Induced Pressure. Based on formula (5), the evolution of the plastic zone and the failure of surrounding rock of the deep roadway under mining-induced pressure were discussed. The diagrams of plastic zone distribution were drawn (Figure 5).

In Figure 5, the parameters are set as follows: $R_{0}=2 \mathrm{~m}$, $c=3 \mathrm{MPa}, \varphi=25^{\circ}$, and $P_{1}=P_{3}=20 \mathrm{MPa}$. It is shown in Figure 5 that the pressure caused by coal mining has

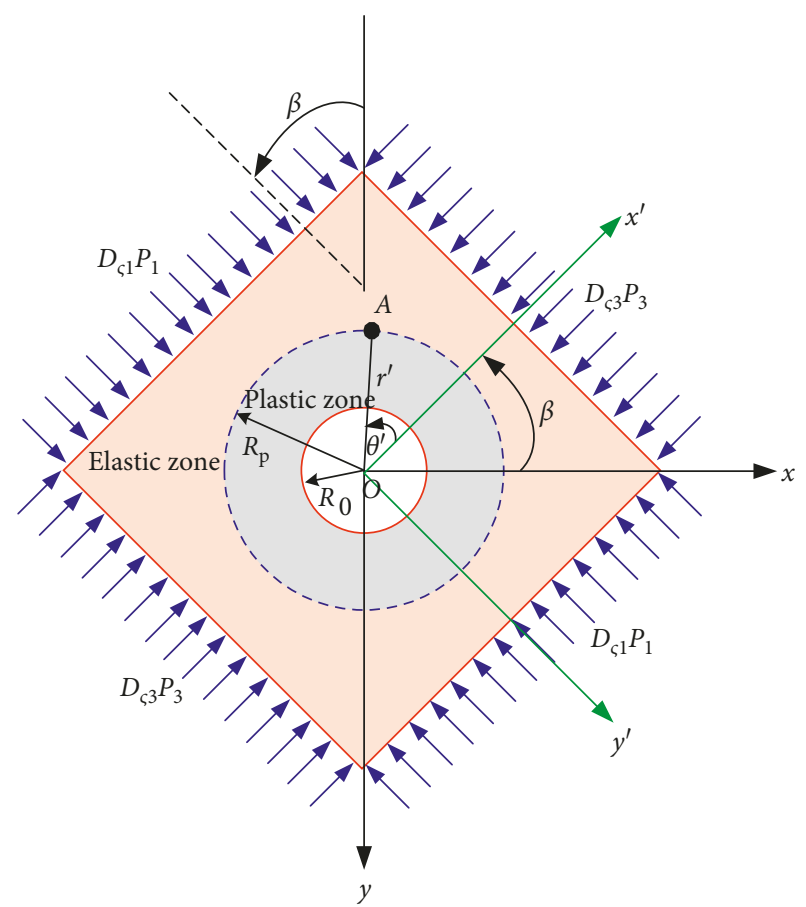

FIGURE 4: Mechanical model of the roadway under deflection of the principal stress field.

significant effect on the distribution of the plastic zone around the deep roadway. The shape of the plastic zone varies with the increase of the pressure difference between horizontal and vertical direction, from circle to ellipse, rounded rectangle, and butterfly shape. Except for the butterfly shape, the dimension of the other three plastic zones is generally between $2.6 \mathrm{~m}$ and $3.2 \mathrm{~m}$, without significant differences. In contrast, the plastic radius of the butterflyshaped plastic zone increases greatly in the inclined direction between the maximum and minimum principal stress due to the formation of the plastic wing, and the maximum plastic radius occurs nearby the bisector of the two directions.

Due to the influence of mining, the butterfly-shaped plastic zone around the deep roadway is more likely to occur. It is observed from Figure 5(a) that, with the increase of the vertical mining coefficient for the maximum principal stress, the plastic wings form and experience a rapid expansion, which present the slender type. For example, the size of the plastic wing grows exponentially during $D_{c 1}$ changing from 2.5 to 2.8 , with the maximum plastic radius $\left(r_{\mathrm{p}, \max }\right)$ of $15 \mathrm{~m}$. This demonstrates that the plastic damage of rock masses within this area is very sensitive to the mining coefficient. Even if the changes of mining influence are small, it may also cause serious localized deformation and failure of the surrounding rock mass. The phenomenon that the shear deformation and failure often occur at the top or bottom corner of the deep roadway under the mining-induced pressure is proved theoretically by the formation and nonlinear extension of the plastic wings, which also shows that the deformation of the mining-influenced roadway is larger than the ordinary one. Thus, it is quite difficult to ensure the stability of the roadway. 


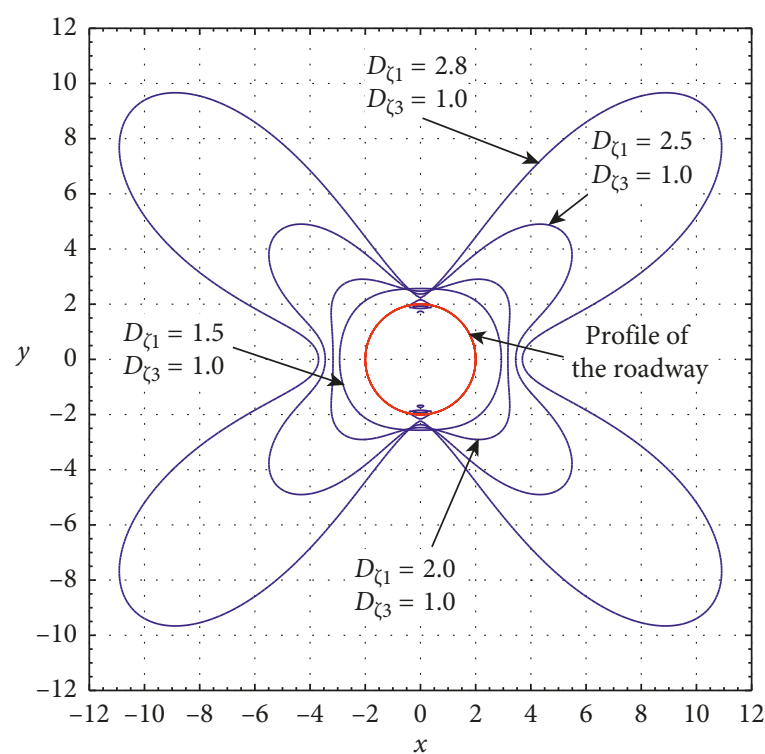

(a)

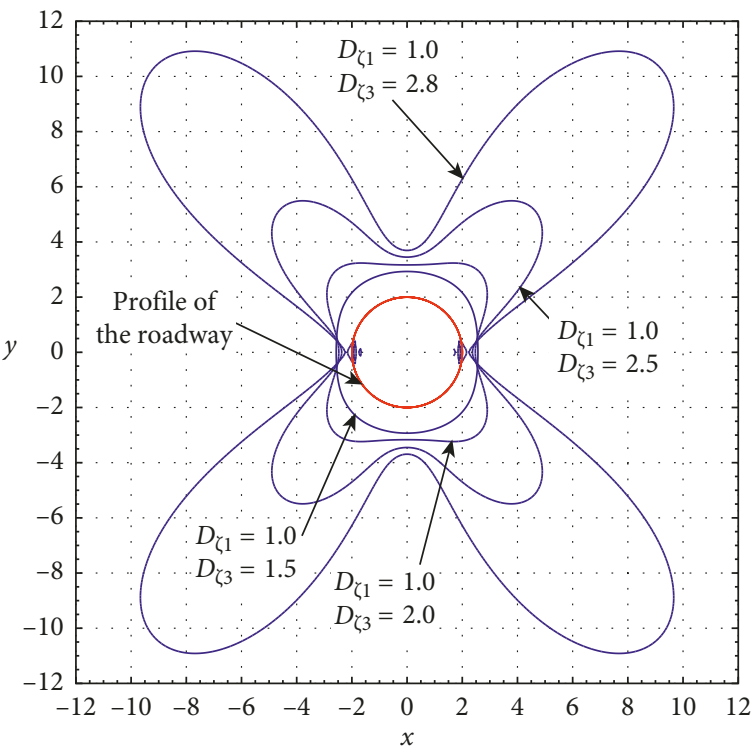

(b)

Figure 5: The plastic zone morphology of the deep roadway (a) influenced by vertical mining-induced pressure and (b) influenced by horizontal mining-induced pressure.

If the direction of the principal stress field for the mininginfluenced roadway rotates, how the morphology of the plastic zone distributes and what is the relationship between the stability of surrounding rock and the morphological characteristics of the plastic zone should be investigated. The distribution diagram of the plastic-zone boundary around the circular roadway is plotted by formula (8), as shown in Figure 6. The parameters are set as follows: $R_{0}=2 \mathrm{~m}$, $c=3 \mathrm{MPa}, \varphi=25^{\circ}, D_{\varsigma 3}=1, D_{\varsigma 1}=2.8$, and $P_{1}=P_{3}=20 \mathrm{MPa}$.

It is found from Figure 6(a) that when the maximum principal stress $D_{\zeta 1} P_{1}$ is perpendicular to the roof stratum of the roadway (i.e., $\beta=0$ ), the maximum depths of plastic damage mainly exist at the top and bottom corner, while the range of the plastic zone in the roof is quite small. With the increase of the deflection angle $\beta$ of the maximum principal stress, the plastic damage of the roadway roof is gradually enlarged, and consequently, the stability of the roof is also deteriorated, as shown in Figure 6(b).

In Figure 6(c), the maximum principal stress is deflected at $\beta=50^{\circ}$, while the four plastic wings are just perpendicular to the sidewalls, floor, and roof. Under the ultrahigh stress field $\left(D_{c 1} P_{1}=42 \mathrm{MPa}\right)$ caused by strong mining, the depth of the plastic wings can reach up to $14 \mathrm{~m}$; therefore, floor heave, roof sinking, and side wall extrusion often occur in the deep mining-affected roadway. It should be pointed out that if the rock mass structure of the roof is poor or the support is improper, the caving risk of the roof rock mass within the plastic wing will be very high. The plastic wings rotate with the continuous rotation of the maximum principal stress, and the area of the plastic zone in the roof decreases gradually, as shown in Figure 6(d).

3.3. Malignant Expansion of the Plastic Zone around a Roadway. Figure 7 shows the effect of $D_{\zeta 1}$ on the plastic radius $r$, and the necessary parameters are set as follows: $R_{0}=2 \mathrm{~m}, c=3 \mathrm{MPa}, \varphi=25^{\circ}$, and $D_{c 3}=1$. The values of $r$ are all taken from the intersection of the plastic wing in the first quartile and the direction of $\theta=\pi / 4$ to represent the maximum plastic radius $r_{p, \max }$. It is seen from Figure 7 that whether, for low stress or for high stress, the curves all can be divided into two stages. During the first stage, the plastic radius keeps increasing near-linearly as the mining coefficient for the maximum principal stress raises, and $r$ can be stabilized at a certain value. When $D_{\zeta 1}$ exceeds the critical value $D_{\zeta \text { c }}$ the second stage starts. Clearly, the growth rate of $r$ increases rapidly and $r$ approaches to infinity finally, which shows that the malignant expansion of the plastic zone occurred. Here, $D_{\zeta c}$ is called the critical mining coefficient. The greater the initial stress, the smaller the value of $D_{\zeta c}$, which indicates that the mining-influenced roadway is more likely to produce malignant expansion of the plastic zone under high stress.

Figure 8 shows the relationship between the radius of the plastic zone and the mining coefficients for the maximum and minimum principal stresses under nonuniform high stress, where $P_{1}=P_{3}=20 \mathrm{MPa}$. When $D_{\zeta 3}$ takes a larger value (3 5), the plastic radius $r$ decreases from the infinite value to the minimum value (at the neutral line) with the rise of $D_{\zeta 1}$, and then it increases to a relatively small value. The neutral line indicates the congruent relationship between $D_{\zeta 1}$ and $D_{\zeta 3}$ when $r$ takes the minimum value. It means that the radius of the plastic zone around the roadway reaches the minimum when the pressure distributes uniformly. The existence of the neutral line proves that one of the principles for the design and support of the deep roadway under mining-induced pressure is that the stress environment of surrounding rock should be improved, and its nonuniformity is required to be minimized for reducing the depth of plastic failure. 


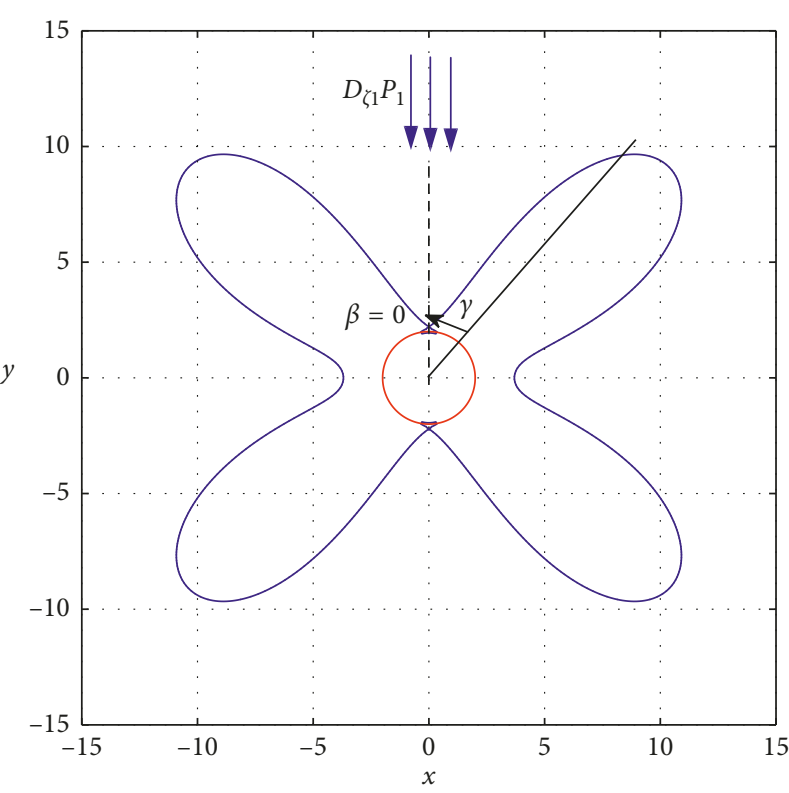

(a)

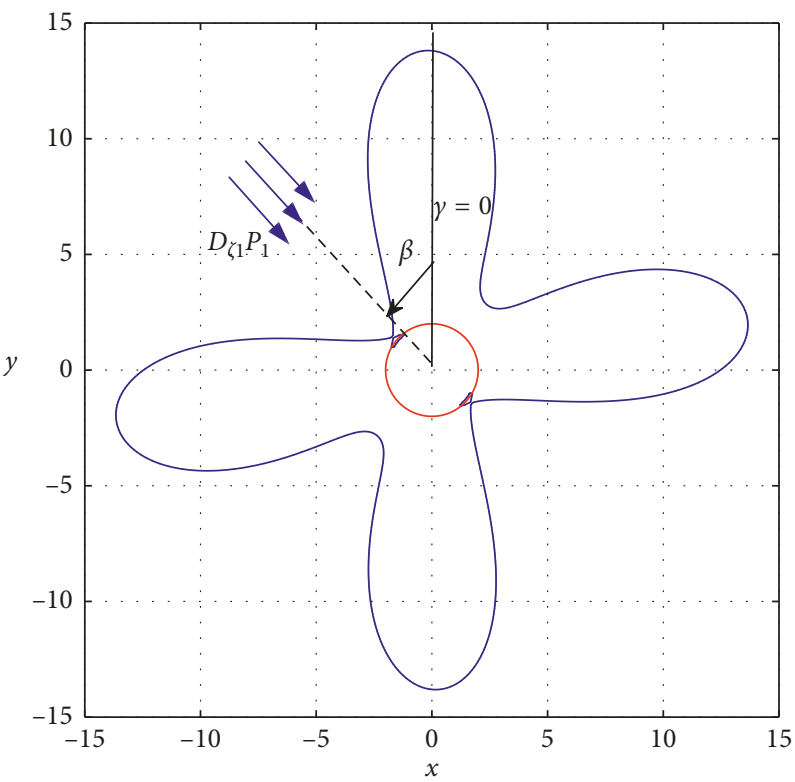

(c)

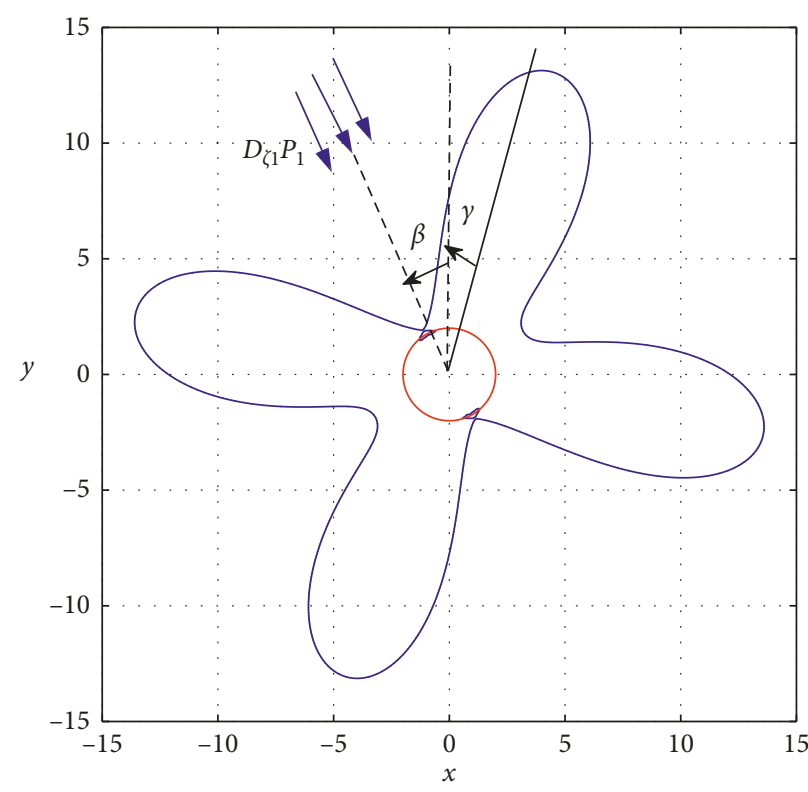

(b)

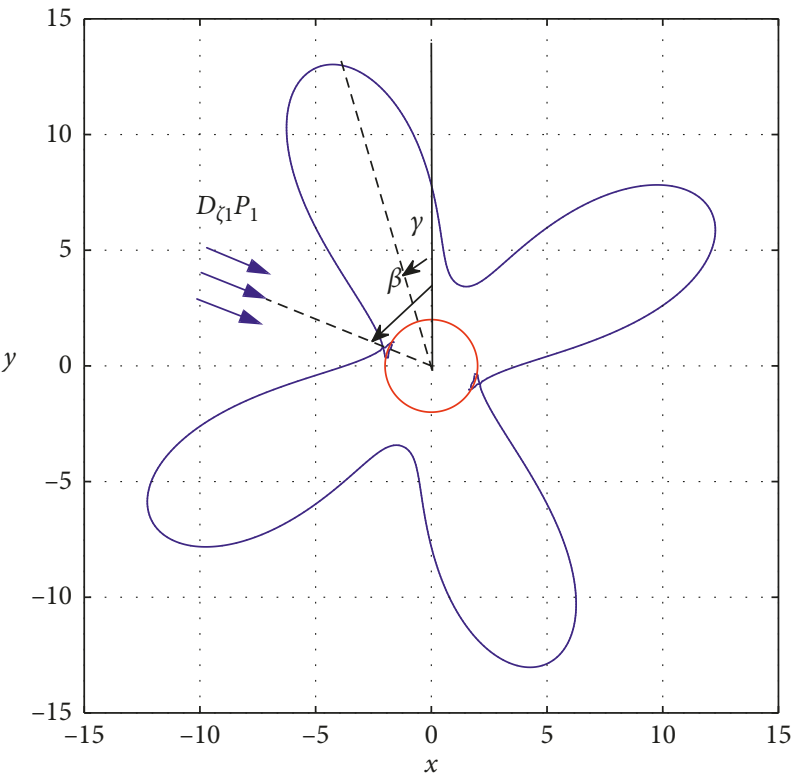

(d)

FIGURE 6: Distribution of the plastic zone around the circular roadway under deflection of the principal stress field: (a) $\beta=0^{\circ}$; (b) $\beta=30^{\circ}$; (c) $\beta=50^{\circ}$; (d) $\beta=70^{\circ}$.

Based on the above analysis, the following definitions are made:

(1) The malignant expansion of the plastic zone (MEPZ): the radius $r$ of the plastic zone increases rapidly with the increase of a certain variable $\xi$; finally, $r$ cannot be stable at a certain magnitude but grows infinitely. This can be expressed as $\lim _{\xi} r(\xi)=\infty$, where $r(\xi)$ is the function of the plastic radius and $\xi_{\mathrm{e}}$ denotes the upper limit of the variable $\xi$.

(2) The criticality for the malignant expansion of the plastic zone $\left(\xi_{c}\right)$ : the plastic radius $r$ increases gradually with the growth of the variable $\xi$; when $\xi$ increases to a certain value $\xi_{c}$, the growth rate of $r$ increases rapidly, and eventually $r$ is approaching infinity. Here, $\xi_{\mathrm{c}}$ is called criticality for the malignant expansion of the plastic zone.

\section{Index System for Morphological Characteristics of Plastic Zone around a Circular Roadway}

In this section, the index system for characterizing the morphological features of the plastic zone around the circular roadway was established using the geometric morphology theory. 


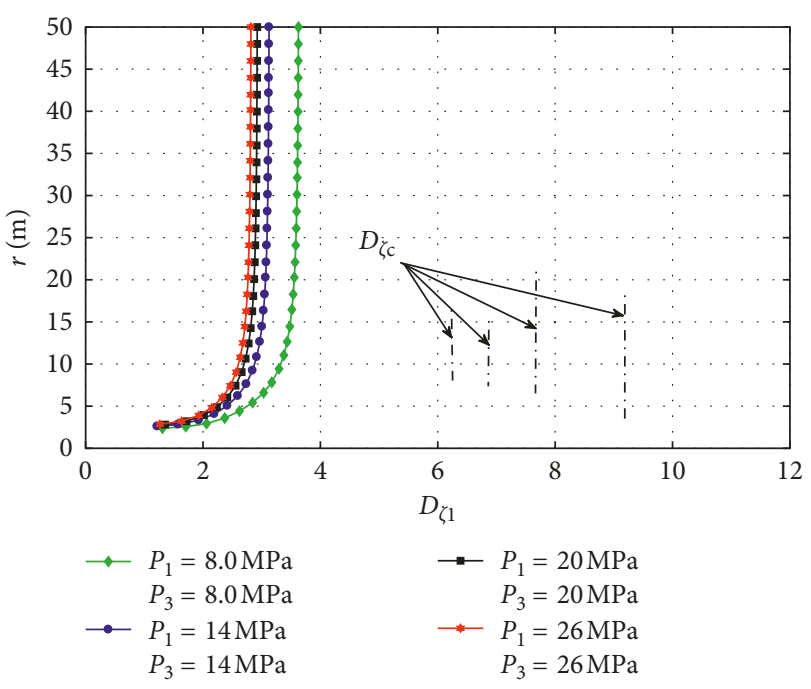

FIgURE 7: Relation curves of $r-D_{\zeta 1}[41]$.

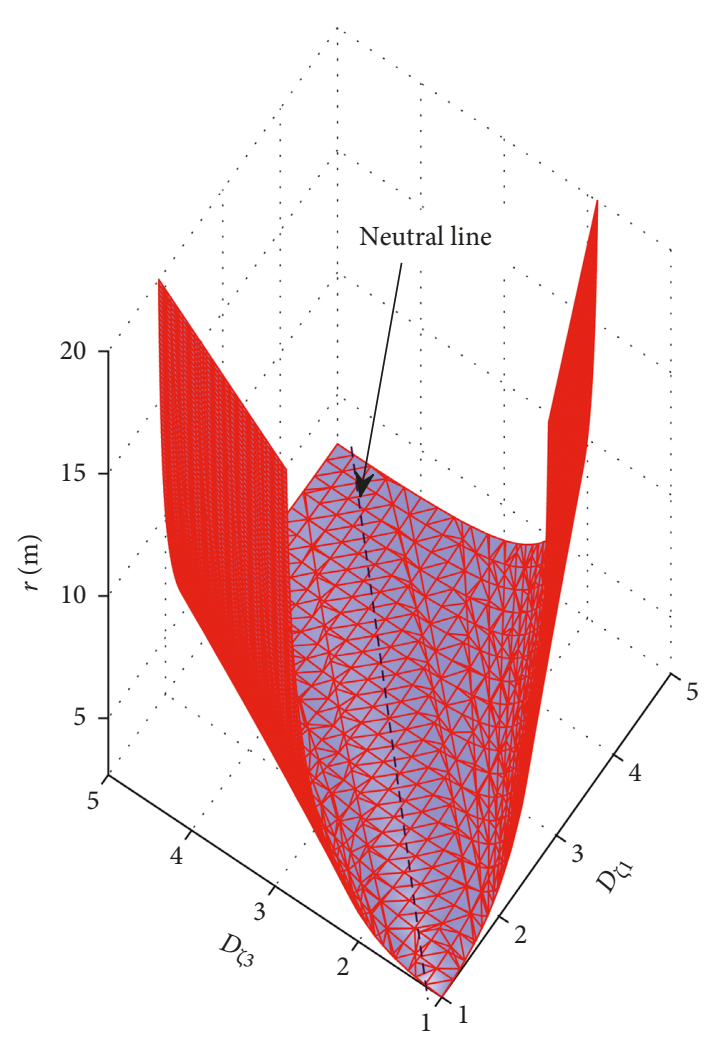

FIGURE 8: The relationship between the radius of the plastic zone and mining coefficients.

4.1. Main Indexes for Morphological Characteristics of the Plastic Zone. Generally, the elastic or plastic solution for the underground roadway is treated as a plane problem, and the plastic failure field obtained is also a 2D figure. Therefore, the indexes established and related parameters are all for the $2 \mathrm{D}$ diagrams.

4.1.1. Uniformity Coefficient $\left(U_{c}\right)$. The uniformity coefficient $U_{c}$ is used to characterize the differences in plastic failure depths on the plastic zone boundary around the circular roadway along any direction from 0 to $2 \pi$. The closer the value of $U_{c}$ is to 1 , the smaller the differences in plastic radius of the plastic zone in all directions are, the closer the shape of the plastic zone is to circle. Generally, the roadway with the circular plastic zone is more stable and has better integrity than those with the heteromorphic plastic zone with the same extension area. $U_{c}$ can be expressed as follows:

$$
U_{\mathrm{c}}=\frac{P_{\mathrm{b}}^{2}}{4 \pi A_{\mathrm{p}}},
$$

where $P_{\mathrm{b}}$ is the perimeter of the plastic zone boundary around the roadway and $A_{\mathrm{p}}$ denotes the area enclosed by the plastic zone boundary.

4.1.2. Extension Factor $\left(E_{f}\right)$. The extension factor $E_{\mathrm{f}}$ is defined as the ratio of the area of the plastic zone of the surrounding rock to sectional area of the roadway. The extension factor reflects the relative size of the plastic zone extension. The larger the $E_{\mathrm{f}}$ is, the larger the range of plastic failure of the surrounding rock is, i.e., the more unstable the surrounding rock mass is. The index of $E_{\mathrm{f}}$ is not only related to the size of the plastic zone but also associated with the dimension of the tunnel. Hence, it is applicable to comparatively analyze the plastic zones around roadways with different sizes. $E_{\mathrm{f}}$ can take the following form:

$$
E_{\mathrm{f}}=\frac{A_{\mathrm{p} 0}}{A_{0}}=\frac{A_{\mathrm{p} 0}}{\pi R_{0}^{2}},
$$

where $R_{0}$ is the radius of the roadway section; $A_{0}$ is the sectional area of the roadway; and $A_{\mathrm{p} 0}$ represents the area of the plastic zone, and it can be obtained from $A_{\mathrm{p} 0}=A_{\mathrm{p}}-A_{0}$.

4.1.3. Equivalent Radius $\left(R_{e q, p}\right)$. The equivalent size and range of the plastic zone can be described by the equivalent radius $R_{\text {eq,p }}$ that is one of the important geometric parameters for intuitively reflecting the macroscopic geometry of the plastic zone. The plastic zone with irregular shape can be transformed into an equivalent circular one in terms of the principle of the same area, shown as the dashed line in Figure 9. The equivalent radius $R_{\text {eq,p }}$ is calculated by the following formula:

$$
R_{\mathrm{eq}, \mathrm{p}}=\sqrt{\frac{A_{\mathrm{p}}}{\pi}} .
$$

4.1.4. Extended Depth Coefficient $\left(E_{d c}\right)$. In order to characterize the relative size of the extended depth for plastic limit, the extended depth coefficient $E_{\mathrm{dc}}$ is introduced. It can be written as follows:

$$
E_{\mathrm{dc}}=\frac{d_{\mathrm{max}}}{R_{0}}
$$

where $d_{\max }$ is the maximum plastic radius of the roadway. The greater the $E_{\mathrm{dc}}$ is, the more serious the plastic failure of surrounding rock is at the direction in which $d_{\max }$ is located. 


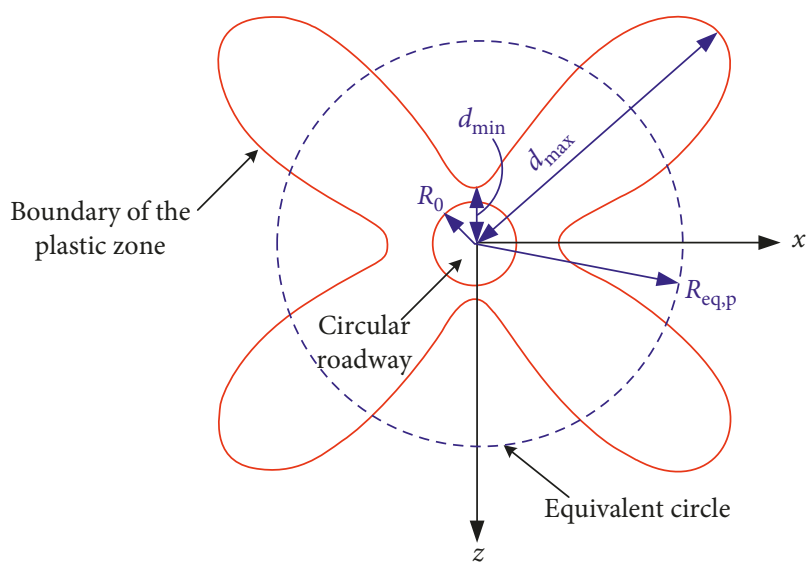

Figure 9: The equivalence of the plastic zone and the geometric parameters.

Although the different roadways have the same $E_{\mathrm{dc}}$ values, the $d_{\max }$ values are not equal. Thus, the local stability of the surrounding rock is also different.

4.1.5. Irregular Shape Coefficient $\left(I_{s c}\right)$. The shape of the plastic zone is closely related to the stability of the roadway. Usually, the roadways with an irregular plastic zone are less stable than those with the regular one due to weak regions in surrounding rock. Then, the index $I_{\mathrm{sc}}$ is used to characterize the degree of irregularity for the shape of the plastic zone. It is defined as the ratio of the maximum plastic radius to the minimum one, given as follows:

$$
I_{\mathrm{sc}}=\frac{d_{\mathrm{max}}}{d_{\min }}
$$

where $d_{\min }$ is the minimum plastic radius of the roadway surrounding rock. The range of the irregular shape coefficient is $I_{\mathrm{sc}} \in[1,+\infty)$; the closer the value of $I_{\mathrm{sc}}$ is to 1 , the more regular the shape of the plastic zone in surrounding rock masses is.

\subsection{Analysisfor Indexes of Morphological Characteristics of the} Plastic Zone. In order to clarify the change of indexes with the evolution of the plastic zone, the plastic zones (Figure 10) with different shapes were analyzed. The conditions for calculation are the same as given in Section 3.2. The relationship between the indexes and $\eta$ is shown in Figures 11-13. $\eta$ is the ratio of the vertical principal stress to the horizontal one, i.e., $\eta=\left(D_{c 1} P_{1} / D_{c 3} P_{3}\right)$.

It can be seen from Figures 10 and 11 that $U_{c}$ and $I_{s c}$ increase continuously with the increase of $\eta$. When $\eta$ exceeds 1.9 , the growth rate of $U_{\mathrm{c}}$ and $I_{\mathrm{sc}}$ becomes larger, which indicates that the differences in the plastic extension depth at various directions are accelerating after the plastic zone evolved into the butterfly shape. Thus, the shape of the plastic zone becomes more irregular, and the stability of the surrounding rock for the roadway is reduced greatly. Additionally, even if the change laws of $U_{\mathrm{c}}$ and $I_{\mathrm{sc}}$ are similar, $I_{\mathrm{sc}}$ is more sensitive to the morphological changes than $U_{\mathrm{c}}$,

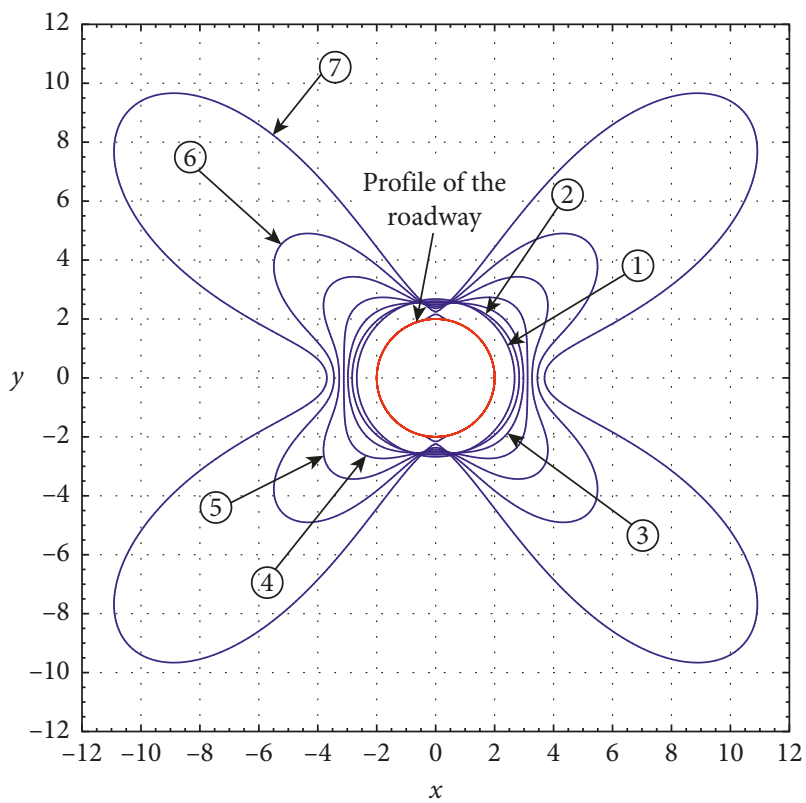

FIgURE 10: The geometrical morphology of the plastic zones.

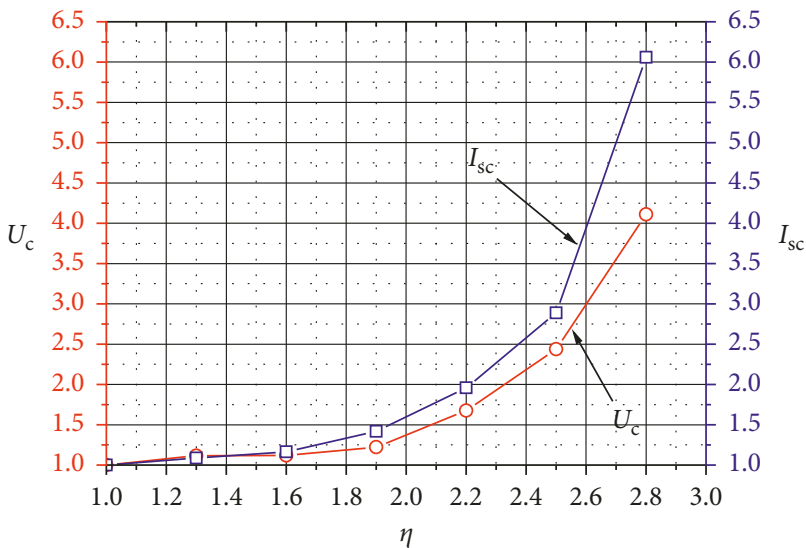

FIgURE 11: The relation curves for $\eta-U_{\mathrm{c}}, I_{\mathrm{sc}}$.

which shows that the differences in morphological changes can be better reflected by the index $I_{\mathrm{sc}}$.

The change process of $E_{\mathrm{f}}$ and $E_{\mathrm{dc}}$ with $\eta$ can be all divided into two stages as shown in Figure 12. The first stage is a slow growth period, and then the second stage of rapid growth starts, which shows that the area of the plastic zone and the limit of extended plastic depth will accelerate when the shape of the plastic zone changes into the butterfly shape. For $\eta>2.2$, the growth rate of the area of the plastic zone is much larger than that of the limit of extended plastic depth, and the overall stability of the surrounding rock will be decreased greatly.

In Figure 13, the equivalent radius $R_{\mathrm{eq}, \mathrm{p}}$ increases approximately at a constant acceleration during the initial stage $(\eta \in[1.0,2.2])$; after that, the accelerating growth stage begins, in which the maximum equivalent radius of the plastic zone can be achieved $(8.805 \mathrm{~m})$. It is far beyond the anchorage range of the rock bolt, which indicates that the size of the plastic zone around the deep roadway under the 


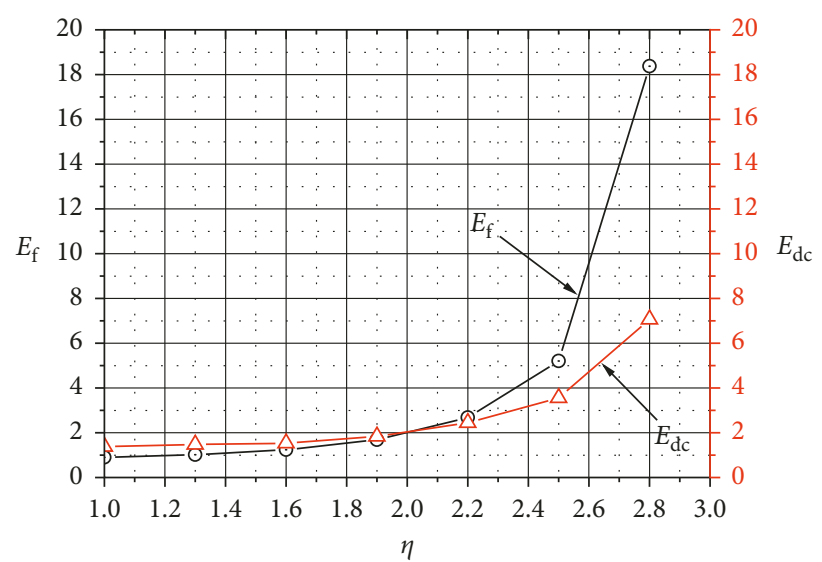

Figure 12: The relation curves for $\eta-E_{\mathrm{f}}, E_{\mathrm{dc}}$.

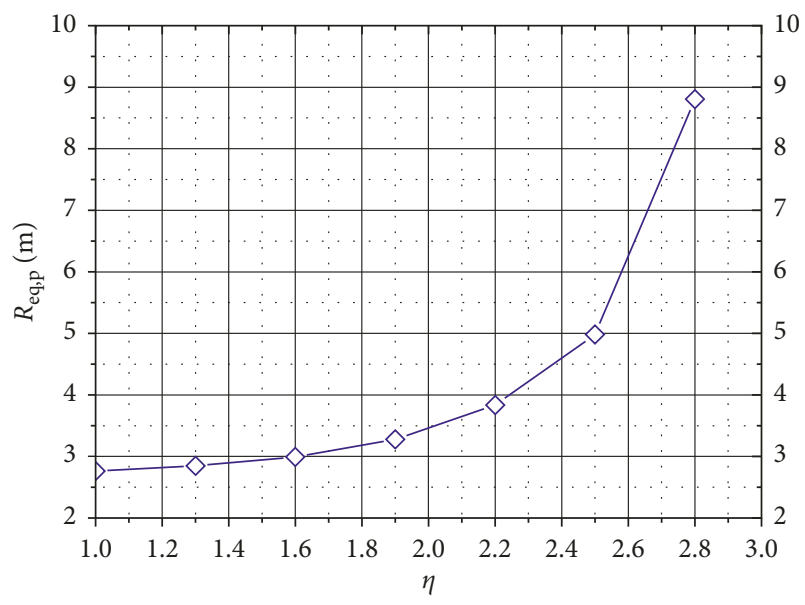

FIgURE 13: The relation curves for $\eta-R_{\text {eq,p }}$.

high deviatoric stress becomes quite large and that the size change of the plastic zone is more sensitive when the plastic zone enters into the stage of butterfly-shaped evolution; therefore, the roadway tends to more easily fail.

\section{Field Validation}

5.1. Project Overview and Failure Status of the Roadway. The \#603 tailgate is located at the west second raise mining area of a coal mine in Jiangxi Province, China. B4 coal seam with the average thickness of $2.8 \mathrm{~m}$ is the main mining object. The design length of \#603 tailgate is $787 \mathrm{~m}$ with a buried depth of $806 \mathrm{~m}$. The geological structure of coalmeasured strata is relatively simple. The immediate roof of this roadway is siltstone with a thickness of $8 \sim 10 \mathrm{~m}$, and the main roof with a thickness of $2 \sim 4 \mathrm{~m}$ is the interbed of siltstone and fine sandstone. While the immediate floor is mudstone with a thickness of $2 \sim 4 \mathrm{~m}$, the main floor of sandstone is $12 \mathrm{~m}$ in thickness.

For the deep coal mining, it is very difficult to maintain the roadways, resulting in unbalance of the mining-drifting. The gate roadways have to be tunneled along the unstable gob before finishing the \#602 working face. Therefore, the \#603 tailgate is not only influenced by the unstable gob but also by the present working face mining. The failure characteristics of \#603 tailgate were obtained by field investigation and testing:

(1) Serious subsidence of the roof stratum and the extrusion of the sidewall occurred. As shown in Figure 14, during the recovery of \#603 working face, the roof had an extremely serious subsidence, leading to large angle lean of the metal pillar, failure of bolts and cables, and localized roof fall. Both sidewalls squeezed out severely, the deformation of a single sidewall was up to $300 \sim 700 \mathrm{~mm}$, and the contraction rate of the roadway section was nearly $40 \%$.

(2) Serious floor heave occurred within the $60 \%$ length of the roadway, which hindered the use of roadway and the normal production of the coal mine.

(3) The distribution characteristics of the failure field in \#603 tailgate surrounding rock were detected in boreholes by the recorder for strata detection, as shown in Figure 15. The results show that the damage depth of surrounding rock reaches nearly $8 \mathrm{~m}$ and the damage range is abnormally large; thus, the strength and integrity of internal rock masses around the roadway deteriorate. The failure depth of the roof and the sidewalls is significantly larger than that of the two top corners, while the failure depth of the roof is larger than that of the sidewalls.

5.2. Analysis for Failure Mechanism of Roadway Based on the Mining-Induced Plastic Zone. According to the field situations, the parameters for calculation are simplified as follows: $R_{0}=2.3 \mathrm{~m}, c=3.3 \mathrm{MPa}, \varphi=27^{\circ}, P_{1}=20.2 \mathrm{MPa}$, and $P_{3}=16 \mathrm{MPa}$. Additionally, $D_{\varsigma 1}=2.4, D_{\varsigma 3}=1.0$, and $\beta=40^{\circ}$ in terms of the past monitoring data for ground pressure. Then, the distribution diagram of the plastic zone around the roadway can be drawn by formula (8), as shown in Figure 16, and the magnitudes of morphological indexes are shown in Table 1. 

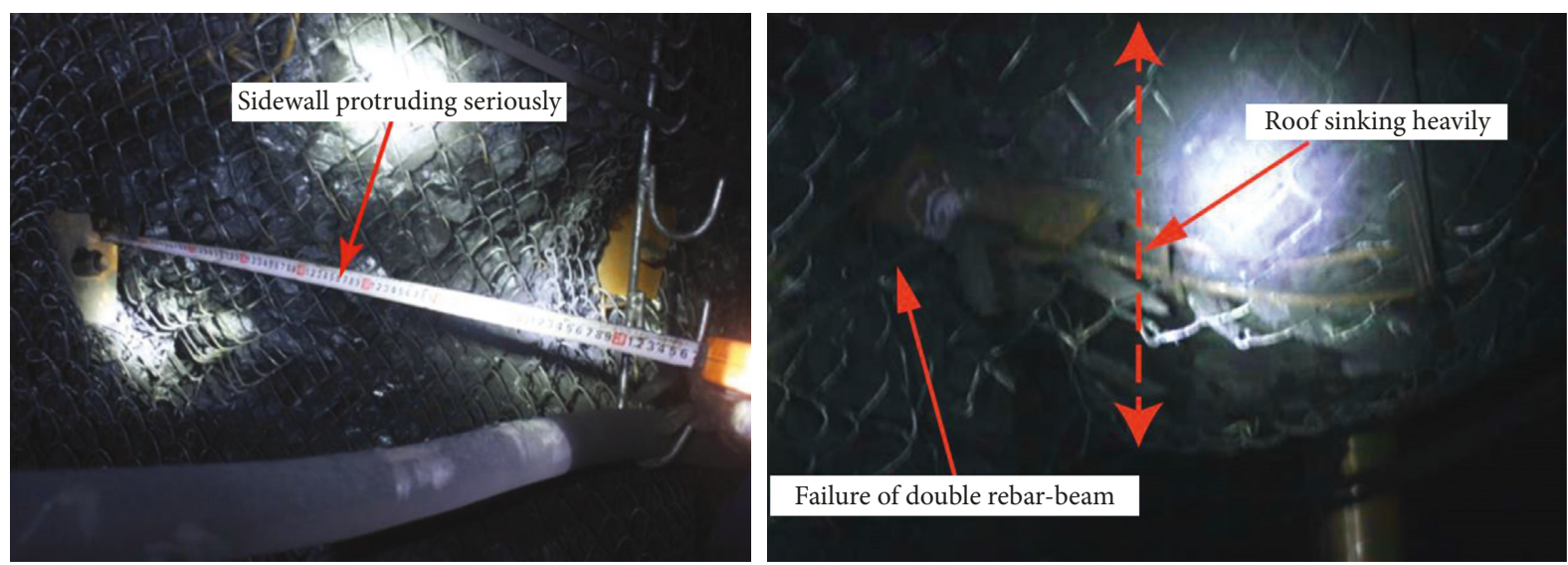

Figure 14: Typical failure modes of surrounding rock masses.

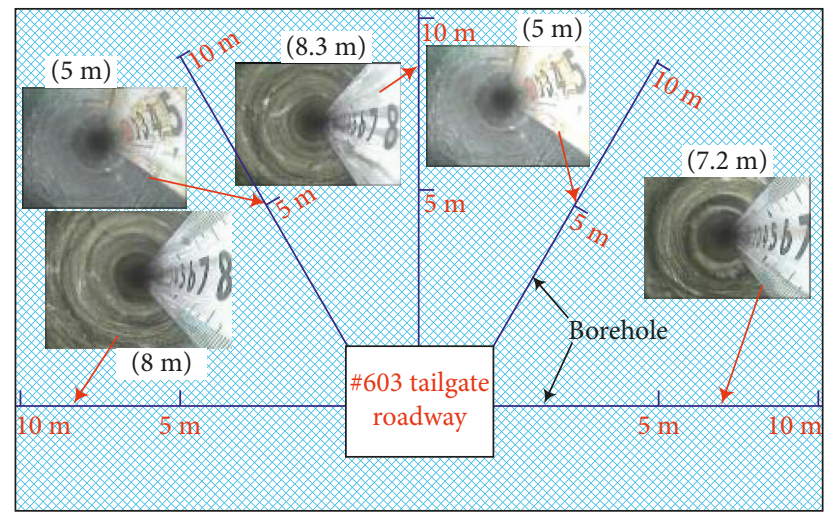

FiguRE 15: Detected results for the failure field of \#603 tailgate.

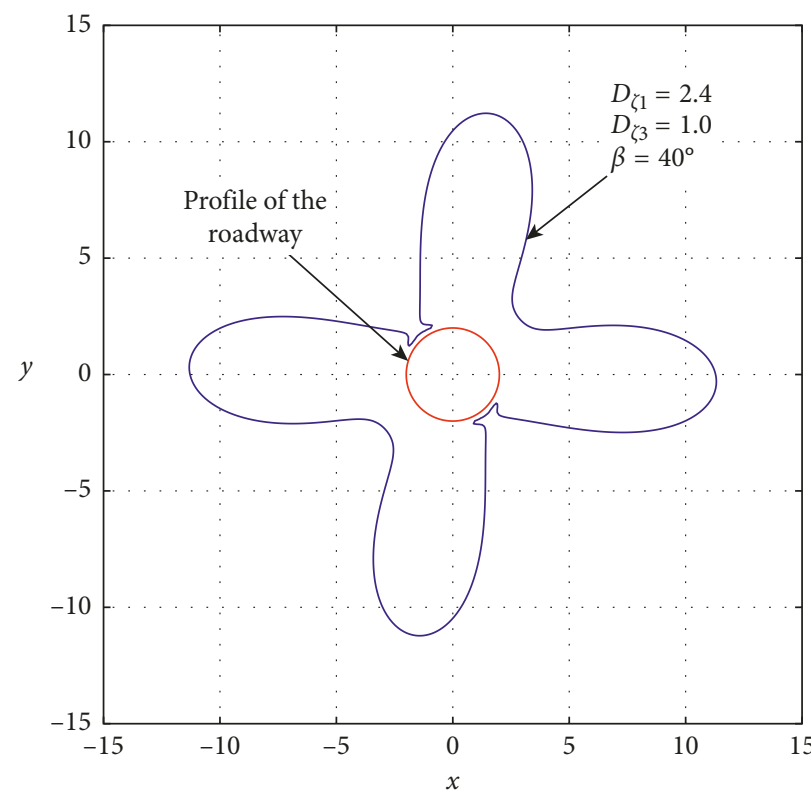

FIGURE 16: Distribution of the plastic zone in surrounding rock.

It can be seen from Figure 16 that the plastic zone of the surrounding rock shows an obvious butterfly shape and the plastic wings extend greatly along the roof, floor, and sidewalls of the roadway. The indexes $U_{\mathrm{c}}=3.46, I_{\mathrm{sc}}=4.98$,
$E_{\mathrm{f}}=12.13$, and $R_{\text {eq,p }}=8.33 \mathrm{~m}$ in Table 1 indicate that the shape of the plastic zone is quite irregular and that the area and dimension of plastic failure in the surrounding rock are very large, especially for the limit of extended depth for the 
Table 1: Magnitudes of morphological indexes for the plastic zone.

\begin{tabular}{lcccccccccc}
\hline \multirow{2}{*}{$\begin{array}{l}\text { Morphology } \\
\end{array}$} & $\eta$ & $d_{\max }(\mathrm{m})$ & $d_{\min }(\mathrm{m})$ & $P_{\mathrm{b}}(\mathrm{m})$ & $A_{\mathrm{p}}\left(\mathrm{m}^{2}\right)$ & $U_{\mathrm{c}}$ & $E_{\mathrm{f}}$ & $R_{\mathrm{eq}, \mathrm{p}}(\mathrm{m})$ & $E_{\mathrm{dc}}$ & $I_{\mathrm{sc}}$ \\
\hline Butterfly shape & 3.03 & 13.24 & 2.66 & 97.39 & 218.23 & 3.46 & 12.13 & 8.33 & 5.76 & 4.98 \\
\hline
\end{tabular}

plastic wings $\left(d_{\max }=13.24 \mathrm{~m}\right)$ which is 5.76 times the radius of the roadway so that it is extremely serious for the plastic deformation and failure of rock masses in these plastic wings grown along the roof, floor, and sidewalls.

Based on the above analysis and the field situation, the failure mechanism of \#603 tailgate is deemed that the soft surrounding rock produced notable deformation in the early stage due to insufficient strength and stiffness of support under high geostress. With the violent influence of roof caving in the gob and mining for \#603 working face, the stress field around the roadway became the ultrahigh, nonuniform stress field; furthermore, the direction of the principal stress deflected, and consequently, a typical butterfly-shaped plastic zone formed (Figure 16). Since the plastic wings with great extended depths were nearly perpendicular to the roof, floor, or sidewalls and the fissures were more developed in surrounding rock, all of them caused nonlinear failure of the surrounding rock of the roadway.

\section{Conclusions}

(1) The analysis of the boundary equation for the plastic zone shows that when considering the influence of mining, the butterfly-shaped plastic zone in surrounding rock is more likely to occur, and the size of the plastic wing and the range of plastic failure are greater than those without consideration. If the plastic wings are approximately perpendicular to the roof, floor, or sidewall, large deformation and failure are very likely to occur for the deep roadway.

(2) The definitions of malignant expansion of the plastic zone and its criticality were made. The effect of mining on the plastic zone around the deep roadway is more sensitive than that on the shallow one. Even if the changes of mining influence are small in short time, it may also cause serious deformation and plastic failure of surrounding rock masses, leading to the sudden instability of the roadway.

(3) The index system for morphological characteristics of the plastic zone around the circular tunnel was built, and the relationship between these indexes and the stability of surrounding rock were deeply analyzed. Compared with $U_{c}, I_{\mathrm{sc}}$ is more sensitive to the morphological changes; thus, the differences in morphological changes can be better reflected by the index $I_{\mathrm{sc}}$.

(4) The failure characteristics of \#603 tailgate were obtained from the field detection and geological conditions. After that, the mechanism of large deformation and failure for \#603 tailgate under deep mining-induced pressure was revealed based on the principles for the formation and extension of the butterfly-shaped plastic zone around the mining-influenced roadway.

\section{Data Availability}

The data (Table 1 and Figures 1 to 16) used to support the findings of this study are included within the article.

\section{Conflicts of Interest}

The authors declare that they have no conflicts of interest.

\section{Acknowledgments}

This work was supported by the Natural Science Foundation of China (Nos. 51504091, 51434006, 51774131, and 51774130) and the Natural Science Foundation of Hunan Province, China (No. 2018JJ3166).

\section{References}

[1] M. C. He, H. P. Xie, S. P. Peng, and Y. D. Jiang, "Study on rock mechanics in deep mining engineering," Chinese Journal of Rock Mechanics and Engineering, vol. 24, no. 16, pp. 28032813, 2005.

[2] M. C. He, W. L. Gong, J. Wang et al., "Development of a novel energy-absorbing bolt with extraordinarily large elongation and constant resistance," International Journal of Rock Mechanics \& Mining Sciences, vol. 67, pp. 29-42, 2014.

[3] C. Fairhurst, "Some challenges of deep mining," Engineering, vol. 3, no. 4, pp. 527-537, 2017.

[4] P. G. Ranjith, J. Zhao, M. H. Ju, R. V. S. D. Silva, T. D. Rathnaweera, and A. K. M. S. Bandara, "Opportunities and challenges in deep mining a brief review," Engineering, vol. 3, no. 4, pp. 546-551, 2017.

[5] Y. L. Zhao, S. L. Luo, and Y. X. Wang, "Numerical analysis of Karst cave water inrush and a criterion for the setting width of water-resistant rock pillar," Mine Water and Environment, vol. 36, no. 4, pp. 508-519, 2017.

[6] X. Chang, X. L. Luo, C. X. Zhu, and C. A. Tang, "Analysis of circular concrete-filled steel tube support in high ground stress conditions," Tunnelling and Underground Space Technology, vol. 43, pp. 41-48, 2014.

[7] Y. L. Zhao, L. Y. Zhang, W. J. Wang, J. Z. Tang, H. Lin, and W. Wan, "Transient pulse test and morphological analysis of single rock fractures," International Journal of Rock Mechanics and Mining Sciences, vol. 91, pp. 139-154, 2017.

[8] Y. L. Zhao, L. Y. Zhang, W. J. Wang, C. Z. Pu, W. Wan, and J. Z. Tang, "Cracking and stress-strain behavior of rock-like material containing two flaws under uniaxial compression," Rock Mechanics and Rock Engineering, vol. 49, no. 7, pp. 2665-2687, 2016. 
[9] M. C. He, "Latest progress of soft rock mechanics and engineering in China," Journal of Rock Mechanics and Geotechnical Engineering, vol. 6, no. 3, pp. 165-179, 2014.

[10] M. Dolezalova, "Tunnel complex unloaded by a deep excavation," Computers and Geotechnics, vol. 28, no. 6-7, pp. 469-493, 2001.

[11] L. S. Jiang, A. Sainoki, H. S. Mitri, N. J. Ma, H. T. Liu, and Z. Hao, "Influence of fracture-induced weakening on coal mine gateroad stability," International Journal of Rock Mechanics \& Mining Sciences, vol. 88, pp. 307-317, 2016.

[12] Q. B. Meng, L. J. Han, Y. Xiao, H. Li, S. Y. Wen, and J. Zhang, "Numerical simulation study of the failure evolution process and failure mode of surrounding rock in deep soft rock roadways," International Journal of Mining Science and Technology, vol. 26, no. 2, pp. 209-221, 2016.

[13] S. Q. Yang, M. Chen, H. W. Jing, K. F. Chen, and B. Meng, "A case study on large deformation failure mechanism of deep soft rock roadway in Xin'an coal mine, China," Engineering Geology, vol. 217, pp. 89-101, 2017.

[14] P. H. S. W. Kulatilake, Q. Wu, Z. X. Yu, and F. X. Jiang, "Investigation of stability of a tunnel in a deep coal mine in China," International Journal of Mining Science and Technology, vol. 23, no. 4, pp. 579-589, 2013.

[15] A. Lisjak, D. Figi, and G. Grasselli, "Fracture development around deep underground excavations Insights from FDEM modeling," Journal of Rock Mechanics and Geotechnical Engineering, vol. 6, no. 6, pp. 493-505, 2014.

[16] X. Fan, K. H. Li, H. P. Lai, Y. L. Xie, R. H. Cao, and J. Zheng, "Internal stress distribution and cracking around flaws and openings of rock block under uniaxial compression: a particle mechanics approach," Computers and Geotechnics, vol. 102, no. 10, pp. 28-38, 2018.

[17] M. C. He, R. L. E. Sousa, A. Müller, J. E. Vargas, L. R. Sousa, and X. Chen, "Analysis of excessive deformations in tunnels for safety evaluation," Tunnelling and Underground Space Technology, vol. 45, pp. 190-202, 2015.

[18] X. M. Sun, F. Chen, M. C. He, W. L. Gong, H. C. Xu, and $\mathrm{H}$. Lu, "Physical modeling of floor heave for the deep-buried roadway excavated in ten degree inclined strata using infrared thermal imaging technology," Tunnelling and Underground Space Technology, vol. 63, pp. 228-243, 2017.

[19] P. Lin, H. Y. Liu, and W. Y. Zhou, "Experimental study on failure behaviour of deep tunnels under high in-situ stresses," Tunnelling and Underground Space Technology, vol. 46, pp. 28-45, 2015.

[20] S. C. Li, Q. Wang, H. T. Wang et al., "Model test study on surrounding rock deformation and failure mechanisms of deep roadways with thick top coal," Tunnelling and Underground Space Technology, vol. 47, pp. 52-63, 2015.

[21] M. Y. Wang, N. Zhang, J. Li, L. J. Ma, and P. X. Fan, "Computational method of large deformation and its application in deep mining tunnel," Tunnelling and Underground Space Technology, vol. 50, pp. 47-53, 2015.

[22] M. R. Zareifard and A. Fahimifar, "Analytical solutions for the stresses and deformations of deep tunnels in an elastic-brittleplastic rock mass considering the damaged zone," Tunnelling and Underground Space Technology, vol. 58, pp. 186-196, 2016.

[23] Q. Wang, R. Pan, and B. Jiang, "Study on failure mechanism of roadway with soft rock in deep coal mine and confined concrete support system," Engineering Failure Analysis, vol. 81, pp. 155-177, 2017.

[24] X. J. Yang, J. W. Pang, D. M. Liu et al., "Deformation mechanism of roadways in deep soft rock at Hegang Xing'an coal mine," International Journal of Mining Science and Technology, vol. 23, pp. 307-312, 2013.

[25] Y. L. Zhao, L. Y. Zhang, W. J. Wang et al., "Creep behavior of intact and cracked limestone under multi-level loading and unloading cycles," Rock Mechanics and Rock Engineering, vol. 50, pp. 1409-1424, 2017.

[26] Y. L. Zhao, L. Y. Zhang, W. J. Wang, W. Wan, and W. H. Ma, "Separation of elastoviscoplastic strains of rock and a nonlinear creep model," International Journal of Geomechanics, vol. 18, no. 1, article 04017129, 2018.

[27] Y. L. Zhao, Y. X. Wang, W. J. Wang, W. Wan, and J. Z. Tang, "Modeling of non-linear rheological behavior of hard rock using triaxial rheological experiment," International Journal of Rock Mechanics \& Mining Sciences, vol. 93, pp. 66-75, 2017.

[28] X. Fan, R. Chen, H. Lin, H. P. Lai, C. Y. Zhang, and Q. H. Zhao, "Cracking and failure in rock specimen containing combined flaw and hole under uniaxial compression," Advances in Civil Engineering, vol. 2018, Article ID 9818250, 15 pages, 2018.

[29] X. B. Li and L. Weng, "Numerical investigation on fracturing behaviors of deep-buried opening under dynamic disturbance," Tunnelling and Underground Space Technology, vol. 54, pp. 61-72, 2016.

[30] F. Q. Gao, D. Stead, and H. P. Kang, "Numerical simulation of squeezing failure in a coal mine roadway due to mininginduced stresses," Rock Mechanics and Rock Engineering, vol. 48, no. 4, pp. 1635-1645, 2015.

[31] J. S. Tian and S. Gao, "Deformation and failure study of surrounding rocks of dynamic pressure roadways in deep mines," Mining Science and Technology, vol. 20, no. 6, pp. 0850-0854, 2010.

[32] H. W. Wang, Y. D. Jiang, S. Xue et al., "Influence of fault slip on mining-induced pressure and optimization of roadway support design in fault-influenced zone," Journal of Rock Mechanics and Geotechnical Engineering, vol. 8, no. 5, pp. 660-671, 2016.

[33] J. H. Zhang, L. G. Wang, Q. H. Li, and S. S. Zhu, "Plastic zone analysis and support optimization of shallow roadway with weakly cemented soft strata," International Journal of Mining Science and Technology, vol. 25, no. 3, pp. 395-400, 2015.

[34] C. Li, J. H. Xu, J. Z. Pan, and C. Ma, "Plastic zone distribution laws and its types of surrounding rock in large-span roadway," International Journal of Mining Science and Technology, vol. 22, no. 1, pp. 23-28, 2012.

[35] C. J. Hou, "Review of roadway control in soft surrounding rock under dynamic pressure," Journal of Coa Science \& Engineering, vol. 9, no. 1, pp. 1-7, 2003.

[36] G. Y. Gao, Q. S. Chen, Q. S. Zhang, and G. Q. Chen, “Analytical elasto-plastic solution for stress and plastic zone of surrounding rock in cold region tunnels," Cold Regions Science and Technology, vol. 72, pp. 50-57, 2012.

[37] S. Sugimoto, H. Ochiai, N. Yasufuku, A. Kawamura, and H. Imanishi, "Estimation of extended plastic zone in the ground with the deformation of cylindrical cavity," Tunnelling and Underground Space Technology, vol. 19pp. 383-384, 2004.

[38] Y. Y. Xiang and S. Q. Feng, "Theoretical prediction of the potential plastic zone of shallow tunneling in vicinity of pile foundation in soils," Tunnelling and Underground Space Technology, vol. 38, pp. 115-121, 2013.

[39] M. B. Reed, P. Grasso, D. Rizzi, and G. Rabajoli, "Improvement of rock properties by bolting in the plastic zone around a tunnel: a numerical study," International Journal of Rock Mechanics and Mining Science \& Geomechanics, vol. 30, no. 5, pp. 567-571, 1993. 
[40] Y. Wang, P. Guo, W. Ren et al., "Laboratory investigation on strength characteristics of expansive soil treated with jute fiber reinforcement," International Journal of Geomechanics, vol. 17, no. 11, article 04017101, 2017.

[41] Y. Yuan, W. J. Wang, C. Yuan, W. J. Yu, H. Wu, and W. Q. Peng, "Large deformation failure mechanism of surrounding rock for gateroad under dynamic pressure in deep coal mine," Journal of China Coal Society, vol. 41, no. 12, pp. 2940-2950, 2016. 


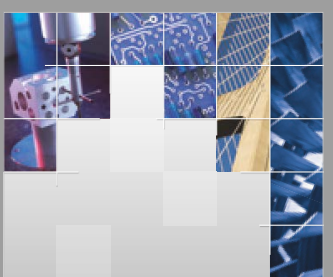

\section{Enfincering}
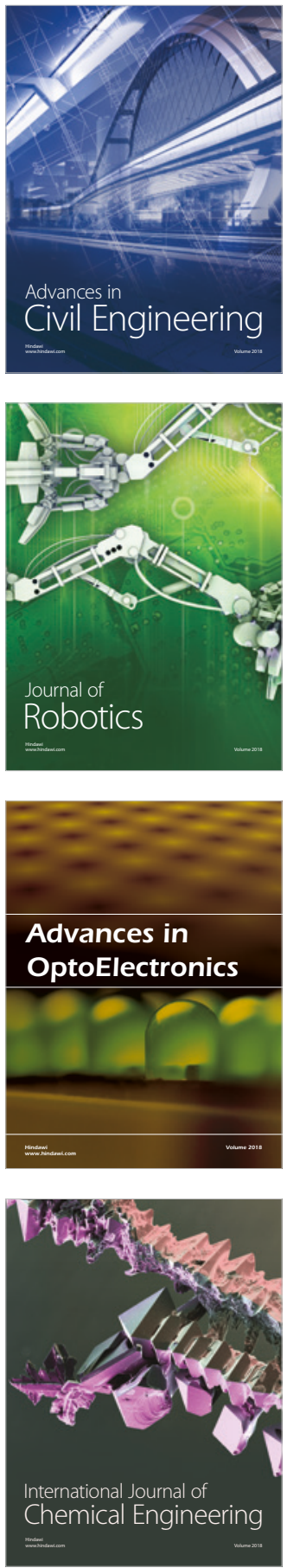

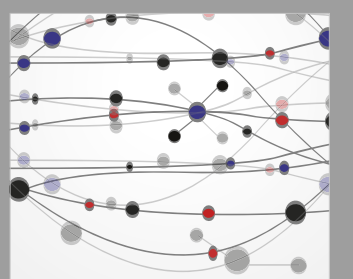

\section{Rotating \\ Machinery}

The Scientific World Journal

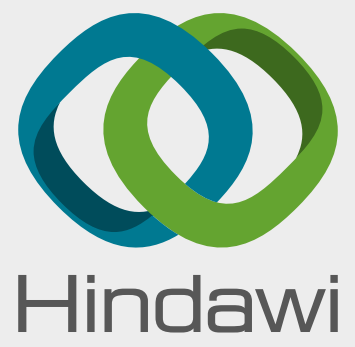

Submit your manuscripts at

www.hindawi.com
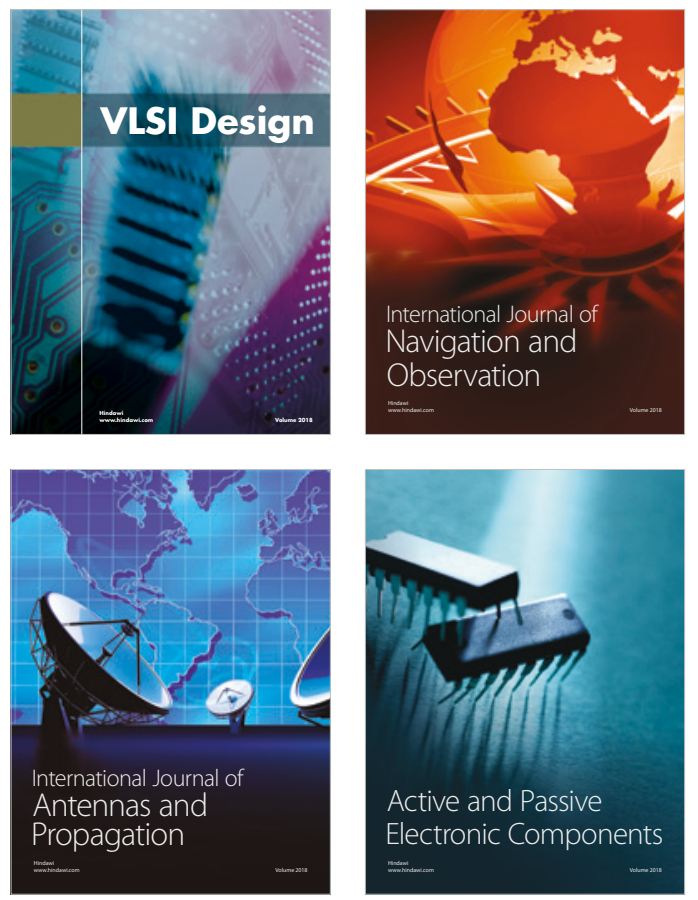
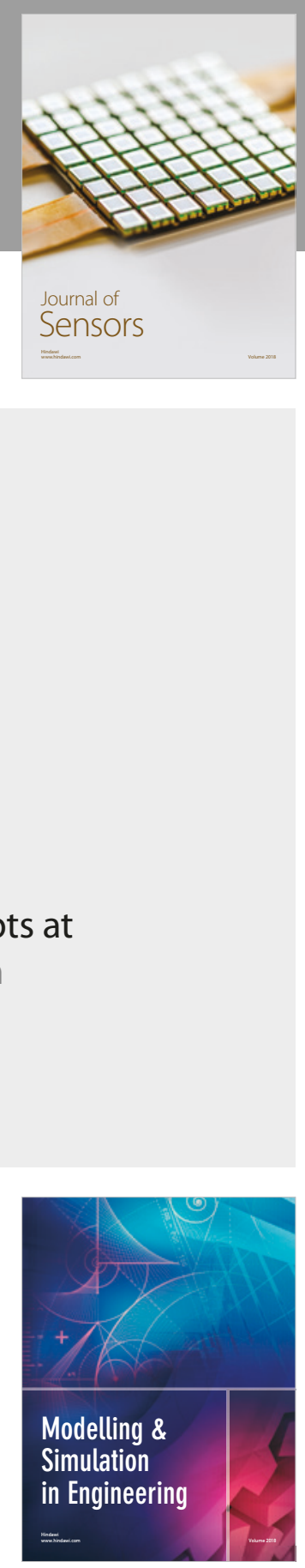

\section{Advances \\ Multimedia}
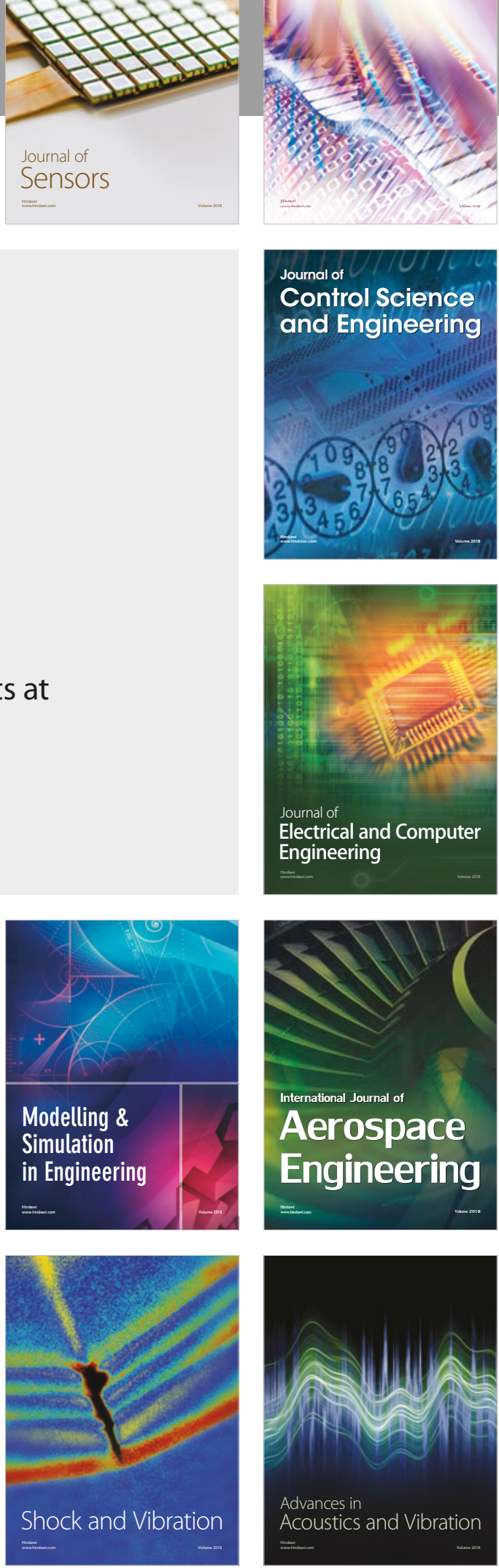